\title{
Physical and psychological effects of postural educational intervention for students experienced school refusal
}

\author{
Maki Maekawa $^{1}$ (I) $\cdot$ Eri Yoshizawa $^{2} \cdot$ Gou Hayata $^{1} \cdot$ Setsuko Ohashi $^{3}$
}

Accepted: 24 March 2021 / Published online: 12 April 2021

(C) The Author(s) 2021

\begin{abstract}
Poor posture has been shown to decrease both visceral and respiratory/circulatory function as well as to increase neuromusculoskeletal system stress. Improper postures of children at school and in daily life can affect their physical and psychological development. In particular, many children who refuse to go to school or who have experienced school refusal have physical and mental problems. Given that posture is closely related to one's psychological state, modifying one's posture can improve both physical and psychological health problems. This study examined the changes to school-refusing students' physical and psychological condition after attending an intervention to improve their posture. The participants were 65 high school students who have experienced school refusal and were attending a program to modify their posture for 2 months. Their posture and psychological states were recorded both pre- and post-intervention with the following measurements: postural alignment and spinal curve according to a sagittal plane, the General Health Questionnaire 30 (GHQ), and the Subjective Adjustment Scale (SAS). Post-intervention, most of the participants saw improvement in their postural alignment (e.g., trunk inclination in standing position, $P<0.001,95 \% \mathrm{CI}[2.00,4.00])$. Participants with improved standing posture post-intervention had higher SAS scores (e.g., feeling of acceptance and trust, $P<0.05,95 \% \mathrm{CI}[-3.00,-0.00]$ ). We found that easy-to-implement postural interventions have a positive effect on students' mental health. Furthermore, it was suggested that their adjustment to school would also improve as their posture improved. The contribution of this study shows that it is possible to care for the physical and mental health of students without using special facilities and techniques. It is hoped that the findings of this study will lead to an improved adjustment to both school or novel environments, as well as prevent health-based school refusal.
\end{abstract}

Keywords Posture $\cdot$ School-refusing students $\cdot$ Physical health $\cdot$ Psychological health

\section{Background}

Posture is closely related to health. Good posture is essential for maintaining good health, while bad posture results in

Current Themes of Research

- Importance of Posture Education in School Education.

- Think about children's health from physical and psychological aspects.

Most Relevant Publications

- No previous publication.

Maki Maekawa

m.maekawa@ipu-japan.ac.jp

1 Department of Physical Education, International Pacific University, 721 Kannonji, Seto-cho, Higashi-ku, Okayama 709-0863, Japan

2 Department of Social Welfare, Seisa Dohto University, 149 Nakanosawa, Kitahiroshima-shi, Hokkaido 061-1196, Japan

3 Department of Early Childhood Development, International Pacific University, 721 Kannonji, Seto-cho, Higashi-ku, Okayama 709-0863, Japan various negative symptoms. With proper posture, the human spine takes a natural physiological curvature, exhibiting an alignment called the cervical and lumbar lordosis, thoracic and sacral kyphosis (Diebo et al., 2015; Neumann et al., 2017). A proper physiological position in the sagittal plane presents a straight line through the mastoid process- acromion - hip joint- slightly in front of the knee joint - lateral malleolus (or slightly in front of it). With proper posture, the line connecting these points overlaps with the center of gravity (Kendall et al., 2010; Czaprowski et al., 2018). This kind of posture reportedly ensures stability with adequate distribution across muscular, skeletal, and nerve loads, as well as maximizing energy efficiency (Kendall et al., 2010; Diebo et al., 2015). However, deviation from the ideal postural arrangement can lead to muscle tension and shortening and excessive loading of joint structures. This can cause functional and structural pathologies, such as headaches, neck and shoulder pain, degenerative intervertebral discs, and herniated intervertebral discs (Feldman et al., 2001; Adams et al., 2009; Barrey et al., 2013; Czaprowski et al., 2018; Paranjape \& Singhania, 
2019). Soft tissue damage can also occur around the joint, involving muscles, tendons, ligaments, and fascia (MayouxBenhamou \& Revel, 1993; Harrison et al., 2005).

Previous studies on children's posture and health problems suggest that poor posture in childhood may lead to the aforementioned problems later in adult life (Feldman et al., 2001; Mackenzie et al., 2003; Murphy et al., 2004; Penha et al. 2005). Children's posture is affected by intrinsic and extrinsic factors such as genetics, environment, physical activity, socioeconomic status, and psychological and physiological states that manifest the process of human growth and development (Chansirinukor et al., 2001; Widhe, 2001; Sheir-Neiss et al., 2003). Several studies show that inappropriate posture adopted by children at school and in daily life can lead to abnormalities in postural development (Chansirinukor et al., 2001, Mackenzie et al., 2003; Penha et al., 2005; SantonjaMedina et al., 2020). Furthermore, movement associated with improper posture may damage the musculoskeletal system, limit activities in daily life, and generally reduce the quality of life (Griegel-Morris et al., 1992; Blondel et al., 2012; Diebo et al., 2015). Thus, it is extremely important for children to acquire proper posture early.

This study focuses on health problems faced by school refusal students through an assessment of their posture. Numerous studies have shown that school refusal students are associated with specific physical and psychological health problems including headaches (Breuner et al., 2004; Rousseau-Salvador et al., 2014), sleep disorders and daytime sleepiness (Tomoda et al., 1997; Hochadel et al., 2014), chronic fatigue syndrome (Miike et al., 2004; Knight et al., 2018), chronic illness and pain (Chalkiadis, 2001; Jastrowski Mano, 2017; Gibler et al., 2019), various anxiety disorders, specific phobias, and depression (Egger et al., 2003; Romani et al., 2017; Gonzalvez et al., 2018). In fact, the students who experienced school refusal belonging to our educational institution have several psychological and physical disorders, such as anterior direction of the head and excessive curvature of the spinal column. Posture and psychological state are closely related, and mutually influence each other (Glaser \& Kiecolt-Glaser, 2005; Nair et al., 2015). Furthermore, it has been reported that the better the mental health, the better the subjective adjustment to school (Okubo, 2005). In the previous study examining the psychological effects of postural interventions, HwangBo (2016) showed positive effects in Cobb angle improvement and depression and self-esteem with the Schroth and Pilates Exercise. Harvey et al. (2020) also found that postural feedback training improved subjective posture and the SF-36 in physical functioning, emotion, energy/ fatigue, confidence, and overall stress ratings. Therefore, it is considered that modifying the posture can reduce or improve physical and mental disorders, enhance physical and mental health, and eventually lead to a better subjective school adjustment. However, little research exists on the changes in physical and psychological status associated with improved posture in relation to school refusal.

In the first place, not only students who have experienced school refusal, but also children are exposed to stressful environments such as bullying, delinquency, and suicide problems. Schools are strongly required to contribute to providing psychological care to students. However, Japanese high schools do not allow them to freely receive school counseling at any time. For example, according to the 2019 School Health Statistics Survey conducted by Japan's Ministry of Education, Culture, Sports, Science and Technology, $43.6 \%$ of the 1410 high schools nationwide surveyed had a school counselor regularly assigned for four or more hours a week. Therefore, we should not rely solely on school counseling, but foster children's ability to maintain and recover their mental health through daily efforts.

As an example of educational initiatives, Lee (2020) found that children's arts and learning skills, attitudes on diversity and being kind-to-each-other, and prosocial skills improved through hands-on arts experiences. Gamble and Crouse (2020) provide strategies to support resilience through the development and nurturing of a set of skills (e.g., taking care of physical health and well-being; keeping things in perspective) using graphic novels, mandala, handbooks, workshops, for students in post-secondary institutions. In addition, Ohashi and Kaneko (2014) reported that through performance activities such as plays, laps, dances, songs, sword fights, and improvisations, indicators of mental health such as resilience and self-esteem, of students who have experienced school refusal increased as the grade progresses. This suggests that daily educational activities can maintain and improve the mental health of children, including students who have experienced school refusal. In this study, we will use stretching (postural intervention), which can be easily performed by oneself in daily life, as a means to verify the effect on physical and psychological care of children.

To address the issue of not having easy access to school counseling, one of our roles is to support the mental health of students who have experienced school refusal by intervening in posture using an easy way, and to improve school adjustment. This study examines the changes in physical and psychological health in these students after an intervention to improve their posture. The study uses a one-group pre-test/post-test design. The concepts applied to PICO are: P (school refusing student), I (postural modification program), C (pre-post intervention), and $\mathrm{O}$ (posture improving, mental health (GHQ), followed by subjective adjustment (SAS). This study can help students adjust to both school and novel environments, as well as prevent health-based school refusal. 


\section{Methods}

\section{Participants}

The participants in this study comprised 65 high school students (46 males and 19 females; mean age, $15.3 \pm 0.5$ years) who attended a wide area correspondence high school in our educational institution and who had been experiencing school refusal. Mean height, weight, and foot length were $164.8 \pm 8.7$ $\mathrm{cm}, 53.0 \pm 11.1 \mathrm{~kg}$, and $25.1 \pm 1.7 \mathrm{~cm}$, respectively. All participants received detailed information about the aims of the study. Informed consent was obtained from all the participants and their parents. The study was approved by the ethics committee at the International Pacific University.

\section{Procedure}

This study was based on a one-group pre-test/post-test design. The data collected before the intervention included the participants' posture measurements and a questionnaire survey filled in by all participants. After the 2-month-long intervention, the participants' posture was remeasured, and they completed the questionnaire. The outline of the procedure is shown below.

\begin{tabular}{|c|c|c|}
\hline \multicolumn{3}{|c|}{ Postural Modification Pprogram } \\
\hline$<$ Pre-measurement $>$ & Feedback \& & $<$ Post - measurement $>$ \\
Postural alignment & Postural & Postural alignment \\
Spinal curvatures & intervention & Spinal curvatures \\
Questionnaire survey $(G H Q, S A S)$ & $\langle 2$ months $\rangle$ & Questionnaire survey $($ GHQ,SAS) \\
\hline
\end{tabular}

\section{Measurement and Evaluation of Postural Alignment during Quiet Standing}

Participants were asked to stand barefoot with their feet parallel to each other and $10 \mathrm{~cm}$ apart. They were instructed to keep their usual standing posture as relaxed as possible and to gaze at a fixed point at the height of their visual line. The reflective marker was then recorded at the following landmarks on the left side: auricular lobule, acromion, the midpoint of the greater trochanter, lateral condyle of the femur, and lateral malleolus. A picture was taken of each of the participants' whole standing posture from the sagittal plane. The ideal alignment line was defined as being $3 \mathrm{~cm}$ in front of the lateral malleolus. The distance between the ideal alignment and each of the markers was then evaluated.

\section{Measurement and Evaluation of Spinal Curvatures}

The sagittal spinal curvatures and pelvic tilt were measured in the usual standing posture using the Spinal Mouse System (Idiag, Fehraltorf, Switzerland), a handheld, computerassisted electromechanical device which measures the sagittal spinal range of motion and intersegmental angles in a noninvasive way. The device is guided along the midline of the spine starting from the spinous process of $\mathrm{C} 7$ and finishing at approximately S3 at the top of the anal crease. These landmarks were determined by palpation at first, after which the two rolling wheels of the mouse were used to follow the spinous processes of the spine to measure the distance and angle. These measurements were transferred from the device to a personal computer. The data was sampled every $1.3 \mathrm{~mm}$ as the mouse rolled along the spine, with a sampling frequency of approximately $150 \mathrm{~Hz}$.

The following positions were recorded: the thoracic spine (T1-T2 to T11-T12), the lumbar spine (T12-L1 to the sacrum), the sacrum and the hips (the difference between the sacral angle and the vertical plane), and the trunk angle of inclination (the angle subtended between the vertical and a line joining $\mathrm{C} 7$ to the sacrum). These were defined as the thoracic kyphosis angle, lumbar lordosis angle, sacral inclination angle, and trunk inclination angle, respectively. Any negative values corresponded to lumbar lordosis or posterior inclination. The participants were examined wearing thin underwear. Similar to the previous measurement, the participants were asked to stand barefoot with their feet parallel to each other and $10 \mathrm{~cm}$ apart. They were instructed to keep their usual standing posture as relaxed as possible and to gaze at a fixed point at the height of their visual line. Three test positions were used: (1) standing upright (in a normal position, knees straight, arms hanging by the side), (2) maximal flexion (legs straight, trunk flexed as far as comfortably possible in an attempt to curl the head into the knees, and arms hanging by the side), and (3) maximal extension (legs straight, arms hanging by the side, head in a neutral position, and trunk extended as far as comfortably possible).

\section{Questionnaire Survey for Physical and Psychological Health}

The General Health Questionnaire 30 (GHQ) is a 30-item selfreport measure of physical and psychological states designed for adults and children aged 12 years or over. The GHQ 
consists of six subscales: general illness (five items), somatic symptoms (five items), sleep disturbance (five items), social dysfunction (five items), anxiety and dysphoria (five items), and suicidal depression (five items). In this study, the five items relating to the suicidal depression subscale were excluded to avoid any negative psychological impact on the participants. The reliability and validity of the Japanese version of the GHQ have previously been evaluated (Nakagawa \& Daibou, 1985).

The Subjective Adjustment Scale (SAS) is a 30-item measure assessing adolescents' subjective adjustment to their school life. The SAS consists of four subscales: sense of comfort (11 items), existence of task and purpose ( 7 items), feelings of acceptance and trust (6 items), and absence of feelings of inferiority ( 6 items). The participants were asked to rate the items using a five-point Likert scale from 1 (not at all true) to 5 (extremely true). The reliability and validity of the SAS have previously been evaluated (Okubo, 2005). The reliability measures (Cronbach's $\alpha$ ) at the time of the pre-test in the present survey were .91 (sense of comfort), .86 (existence of task and purpose), .87 (feelings of acceptance and trust), and .77 (absence of feelings of inferiority).

Both surveys were conducted during homeroom class. The homeroom teachers were instructed to inform the participants about the purpose of the survey before distributing the questionnaires and were then responsible for collecting the completed questionnaires. Participants were given a rest period of at least $10 \mathrm{~min}$ between each survey.

\section{The Postural Modification Programs}

The program consisted of two parts. (1) Measurement and feedback of posture: participants were given their results on paper and were shown how to improve their posture to more closely resemble the ideal postural arrangement. (2) Postural intervention: First, to increase flexibility, pressure was applied with fingers on the diaphragm and scalene muscles involved in postural maintenance and respiratory function. The finger pressure to the diaphragm was applied for approximately five seconds using four fingers from index finger to little finger of both hands while the subject exhaled, then the pressure was relaxed and the subject inhaled. These actions were repeated five times. The finger pressure to the oblique was applied to the left and right scalene muscles (around the side of the throat) for approximately five seconds while the subject inhaled, using the index finger of both hands, then the pressure was relaxed and the subject exhaled. These actions were repeated five times.

Next, action was taken to orient the curvature of the spine. To direct the curvature of the cervical vertebrae, participants were instructed to move their heads forward while maintaining their shoulder position, and then bend their heads back smoothly until they were gazing at the ceiling. The head was then slowly moved with the second cervical vertebrae serving as a fulcrum so that the face was facing forward. In order to tilt the pelvis forward and to direct the curvature of the spine, participants maintained a standing position with the chest and abdomen stretched, bent the trunk about $35^{\circ}$ forward with the hip joint serving as a fulcrum, and then the trunk was slowly raised. Subsequently, a neutral position of the pelvis was attained by exerting force on the lower abdomen and pointing the coccyx slightly downward. Finally, both shoulder blades were slightly adducted, and the posture was maintained with the chest stretched. These actions can be easily performed by oneself in 1 to $2 \mathrm{~min}$. For approximately 2 months, participants performed these actions in their homeroom period and at other times of their choosing.

\section{Date Analysis}

All students had the opportunity to participate in this study. However, students who did not consent did not participate, and the data of students who were absent on the measurement date (pre or post) were excluded from the analysis. To evaluate the postural alignment on the sagittal plane, an ideal alignment line was added to participants' photographs (the ideal line defined as being $3 \mathrm{~cm}$ in front of the lateral malleolus). The distance between the vertical line and each of the markers was calculated, and it was indicated as an absolute value from an ideal point. The angle formed by a straight line joining the auricular lobule and acromion and the vertical line was defined as the head-neck angle. In the evaluation of the spinal curvatures, the thoracic kyphosis angle, lumbar lordosis angle, sacral inclination angle, and trunk inclination angle were used, calculated by the Spinal Mouse System and mean values, respectively. The postural alignment was compared with the ideal alignment in the quiet standing position, and the flexibility in the maximal flexion and extension was also evaluated. To examine the change in physical and psychological health states related to posture, participants were classified into two groups: the improved postural group and the non-improved postural group. When the trunk inclination angle standing upright was found to be closer to the ideal alignment after the intervention, the standing posture was defined as improved. When the change was not found or had receded from the ideal alignment, the posture was defined as non-improved. Regarding the maximal flexion and extension, the flexibility of the maximal flexion and extension was defined as improved when an increase in flexibility was found in post-intervention scores. In the GHQ, each item was summed and transformed to get a subscale score ranging from 0 (good) to 5 (bad) and an overall psychological health score ranging from 0 to 25 . In the $\mathrm{SAS}$, each item was summed to produce a subscale score. The score ranges for subscales of SAS were 11-55 (sense of comfort), 7-35 
(existence of task and purpose), and 6-30 (feelings of acceptance and trust, absence of feelings of inferiority).

\section{Statistical Analysis}

Wilcoxon signed-rank tests were used to assess the differences pre- and post-intervention in postural alignment, spinal curvatures, and pelvic tilt. Wilcoxon signed-rank tests were also used to assess the differences pre- and post-intervention in the subscales and total score of the GHQ and the subscales of the SAS. When a significant difference for each of the GHQ and SAS subscales between pre- and post-intervention was not found, additional analyses were conducted. Data of participants were divided into two groups based on they had improved their posture or not. The Mann-Whitney U tests were used to confirm that there were no significant differences between the two groups for the pre-intervention data of each subscale. Then, pre- and post-intervention differences for the dependent variables (GHQ and SAS subscales) were assessed in each group using the Wilcoxon signed-rank test. All statistical analyses were performed using IBM SPSS Statistics 17 (IBM Japan, Japan).

\section{Results}

Table 1 summarizes the medians and quartile deviations of pre- and post-intervention postural alignment parameters, spinal curvatures, pelvic tilt. After the intervention, all the parts measured were modified to resemble a more vertical alignment (auricular lobule, $z=1.73, P=0.08$; acromion, $z=$ 2.55, $P<0.05$; midpoint of the greater trochanter, $z=2.11$, $P<0.05$; lateral condyle of the femur, $z=3.68, P<0.001$ ).
The head-neck angle was found to be significantly smaller after the intervention $(z=2.58, P=0.05)$, as well as the sacral inclination angle and trunk inclination angle (sacral, $z=3.10$, $P<0.01$; trunk, $z=5.10, P<0.001$ ). In the maximal flexion and extension conditions, the trunk inclination angle was found to be significantly larger after the intervention (flexion, $z=5.40, P<0.001$; extension, $z=6.32, P<0.001$ ). No significant differences were found post-intervention in the thoracic kyphosis angle and the lumbar lordosis angle in the standing position.

Table 2 summarizes the medians and quartile deviations of pre- and post-intervention the GHQ and SAS scores. There was a significant decrease in social dysfunction $(z=2.54$, $P<0.05)$, and the GHQ total scores approached a significant decrease $(z=1.74, P=0.08)$. There were no significant differences by intervention in all subscales of SAS.

Table 3 summarizes the medians and quartile deviations of the pre- and post-intervention the GHQ and SAS subscales scores excluding social dysfunction and GHQ total. A Wilcoxon signed-rank test were conducted on the GHQ and SAS scores excluding social dysfunction and GHQ total, using the group with improved/ non-improved as independent variables. The 36 participants in the improved group were found to have modified their trunk inclination, but the 29 participants in the non-improved group did not. Some of the significant effects that were found post-intervention included an increase in the feeling of acceptance and trust in the improved group $(z=2.26$, $P<0.05)$ and a decrease in the non-improved group $(z=1.99$, $P<0.05$ ). In the improved group, the marginally significant was an increase in the sense of comfort $(z=1.65, P=0.10)$. In the non-improved group, the marginally significant was a decrease in the somatic symptoms $(z=1.78, P=0.08)$ and the sense of comfort $(z=1.72, P=0.09)$.

Table 1 The medians and quartile deviations of pre- and post-intervention postural alignment parameters, spinal curvatures, and pelvic tilt

\begin{tabular}{|c|c|c|c|c|c|c|c|c|c|}
\hline & \multirow[t]{2}{*}{ Dependent variables } & \multicolumn{2}{|c|}{$\begin{array}{l}\text { Pre } \\
\text { intervention }\end{array}$} & \multicolumn{2}{|c|}{$\begin{array}{l}\text { Post } \\
\text { intervention }\end{array}$} & \multirow[t]{2}{*}{ Statistical values } & \multirow[t]{2}{*}{ Significance } & \multirow{2}{*}{$\begin{array}{l}\text { Hodges-Lehmann } \\
\text { Estimate }\end{array}$} & \multirow{2}{*}{$\begin{array}{l}95 \% \mathrm{Cl} \text { for } \\
\text { Hodges-Lehmanı } \\
\text { (Lower, Upper) }\end{array}$} \\
\hline & & Median & QD & Median & QD & & & & \\
\hline \multirow[t]{9}{*}{ Standing } & head-neck $\left(^{\circ}\right)$ & 11.10 & 4.25 & 9.00 & 4.60 & $z=2.58$ & $p<0.05$ & 2.40 & $0.70,4.40$ \\
\hline & auricular lobule $(\mathrm{cm})$ & 4.00 & 1.83 & 2.90 & 2.03 & $z=1.73$ & $p=0.08$ & 0.60 & $-0.10,1.25$ \\
\hline & acromion $(\mathrm{cm})$ & 2.10 & 1.25 & 1.00 & 1.33 & $z=2.55$ & $p<0.05$ & 0.70 & $0.20,1.20$ \\
\hline & greater trochanter $(\mathrm{cm})$ & 2.60 & 1.73 & 2.40 & 1.65 & $z=2.11$ & $p<0.05$ & 0.60 & $0.05,1.10$ \\
\hline & lateral condyle $(\mathrm{cm})$ & 1.80 & 0.90 & 1.20 & 0.95 & $z=3.68$ & $p<0.001$ & 0.70 & $0.35,1.05$ \\
\hline & thoracic kyphosis $\left({ }^{\circ}\right)$ & 39.00 & 6.75 & 39.00 & 8.25 & $z=0.72$ & N.S & -1.00 & $-3.00,1.50$ \\
\hline & lumbar inclination $\left(^{\circ}\right)$ & -24.00 & 7.00 & -23.00 & 5.25 & $z=0.69$ & N.S & 0.50 & $-1.00,2.50$ \\
\hline & sacral inclination $\left(^{\circ}\right)$ & 14.00 & 4.00 & 11.00 & 3.75 & $z=3.10$ & $p<0.01$ & 2.50 & $1.00,4.00$ \\
\hline & trunk inclination $\left(^{\circ}\right)$ & 3.00 & 2.75 & 0.00 & 2.50 & $z=5.10$ & $p<0.001$ & 3.00 & $2.00,4.00$ \\
\hline Maximal flexion & trunk inclination $\left(^{\circ}\right)$ & 92.00 & 8.75 & 104.00 & 10.25 & $z=5.40$ & $p<0.001$ & -8.00 & $-11.00,-5.50$ \\
\hline Maximal extension & trunk inclination $\left(^{\circ}\right)$ & -24.00 & 5.00 & -37.00 & 8.50 & $z=6.32$ & $p<0.001$ & -13.00 & $10.50,16.00$ \\
\hline
\end{tabular}

The quartile deviation indicates half of the interquartile range 
Table 2 The medians and quartile deviations of the pre- and post-intervention GHQ and SAS scores

\begin{tabular}{|c|c|c|c|c|c|c|c|c|c|c|}
\hline & \multirow[t]{2}{*}{ Dependent variables } & \multirow{2}{*}{$\begin{array}{l}\text { score } \\
\text { range } \\
\text { min - max }\end{array}$} & \multicolumn{2}{|c|}{ Pre intervention } & \multicolumn{2}{|c|}{ Post intervention } & \multirow{2}{*}{$\begin{array}{l}\text { Statistical } \\
\text { values }\end{array}$} & \multirow[t]{2}{*}{ Significance } & \multirow{2}{*}{$\begin{array}{l}\text { Hodges- } \\
\text { Lehmann } \\
\text { Estimate }\end{array}$} & \multirow{2}{*}{$\begin{array}{l}95 \% \mathrm{Cl} \text { for } \\
\text { Hodges-Lehmanr } \\
\text { Lower, Upper }\end{array}$} \\
\hline & & & Median & QD & Median & QD & & & & \\
\hline \multirow[t]{6}{*}{ GHQ } & general illness & $0-5$ & 1.00 & $(1.00)$ & 1.00 & $(1.00)$ & $z=0.75$ & N.S & 0.00 & $-0.00,0.50$ \\
\hline & somatic symptoms & $0-5$ & 1.00 & $(1.50)$ & 1.00 & $(1.00)$ & $z=1.19$ & N.S & 0.00 & $-0.00,1.00$ \\
\hline & sleep disturbance & $0-5$ & 1.00 & $(1.50)$ & 1.00 & $(1.25)$ & $z=0.55$ & N.S & 0.00 & $-0.50,1.00$ \\
\hline & social dysfunction & $0-5$ & 0.00 & $(0.50)$ & 0.00 & $(0.50)$ & $z=2.54$ & $p<0.05$ & 1.00 & $0.00,1.50$ \\
\hline & anxiety and dysphoria & $0-5$ & 1.00 & $(1.00)$ & 0.00 & $(1.25)$ & $z=0.23$ & N.S & 0.00 & $-0.50,1.00$ \\
\hline & GHQ total & $0-25$ & 5.00 & $(4.50)$ & 5.00 & $(3.00)$ & $z=1.74$ & $p=0.08$ & 1.00 & $-0.00,2.00$ \\
\hline \multirow[t]{4}{*}{ SAS } & sense of comfort & $11-55$ & 38.00 & $(4.50)$ & 39.00 & $(5.00)$ & $z=0.08$ & N.S & 0.00 & $-1.50,1.50$ \\
\hline & existence of task and purpose & $7-35$ & 26.00 & $(2.50)$ & 26.00 & $(2.50)$ & $z=0.12$ & N.S & 0.00 & $-1.00,1.00$ \\
\hline & feelings of acceptance and trust & $6-30$ & 18.00 & $(2.00)$ & 18.00 & $(2.00)$ & $z=0.36$ & N.S & -0.00 & $-1.40,1.00$ \\
\hline & absence of feelings of inferiority & $6-30$ & 19.00 & $(2.00)$ & 19.00 & $(2.00)$ & $z=0.84$ & N.S & -0.50 & $-1.50,0.50$ \\
\hline
\end{tabular}

The quartile deviation indicates half of the interquartile range

A total of 53 participants were found to have increased maximal flexion post-intervention, whereas 12 participants did not. A significant effect was found post-intervention included a decrease in the absence of feelings of inferiority in the non-improved group $(z=1.97, P<0.05)$. In the improved group, the marginally significant was an increase in the absence of feelings of inferiority $(z=1.79, P=0.07)$. A total of 55 participants were found to have increased maximal extension, whereas 10 participants did not. In the non-improved group, the marginally significant was a decrease in the sense of comfort $(z=1.68, P=0.09)$ and the feeling of acceptance and trust $(z=1.69, P=0.09)$.

\section{Discussion}

This study aimed to investigate the physical and psychological changes in school-refusing students after their posture was improved. The results show that trunk inclination in the standing position became more vertical on post-intervention due to the postural modification program. In addition, the flexibility of the maximal flexion and extension was also found to have increased after the intervention. Moreover, the GHQ score, which indicates subjective physical and psychological health, tended to improve, and the sense of school adjustment improved as posture improved.

Table 3 The medians and quartile deviations of the GHQ and SAS scores by the intervention and group

\begin{tabular}{|c|c|c|c|c|c|c|c|c|c|c|c|}
\hline \multirow[t]{2}{*}{ Posture } & \multirow{2}{*}{$\begin{array}{l}\text { Dependent variables } \\
\text { (score range; } \\
\text { min - max) }\end{array}$} & \multirow[t]{2}{*}{ Group } & \multirow[t]{2}{*}{ sample } & \multicolumn{2}{|c|}{ Pre intervention } & \multicolumn{2}{|c|}{ Post intervention } & \multirow{2}{*}{$\begin{array}{l}\text { Statistical } \\
\text { values }\end{array}$} & \multirow[t]{2}{*}{ Significance } & \multirow{2}{*}{$\begin{array}{l}\text { Hodges- } \\
\text { Lehmann } \\
\text { Estimate }\end{array}$} & \multirow{2}{*}{$\begin{array}{l}95 \% \mathrm{Cl} \text { for } \\
\text { Hodges- } \\
\text { Lehmann } \\
\text { Lower, Upper }\end{array}$} \\
\hline & & & & Median & (QD) & Median & (QD) & & & & \\
\hline & somatic symptoms & improved & 36 & 1.00 & $(1.38)$ & 1.00 & $(1.00)$ & $z=0.05$ & N.S & 0.00 & $-1.00,1.00$ \\
\hline & $(0-5)$ & non-improved & 29 & 1.00 & $(1.25)$ & 1.00 & $(1.00)$ & $z=1.78$ & $p=0.08$ & 1.00 & $-0.00,1.50$ \\
\hline & sense of comfort & improved & 36 & 38.00 & $(4.88)$ & 39.50 & $(5.00)$ & $z=1.65$ & $p=0.10$ & -1.50 & $-3.50,0.50$ \\
\hline & $(11-55)$ & non-improved & 29 & 38.00 & $(4.25)$ & 38.00 & $(5.25)$ & $z=1.72$ & $p=0.09$ & 2.00 & $-0.50,4.50$ \\
\hline & $\begin{array}{l}\text { feelings of acceptance } \\
\text { and trust }\end{array}$ & improved & 36 & 18.00 & $(2.00)$ & 18.00 & $(1.90)$ & $z=2.26$ & $p<0.05$ & -1.50 & $-3.00,-0.00$ \\
\hline & $(6-30)$ & non-improved & 29 & 18.00 & $(2.75)$ & 18.00 & $(3.50)$ & $z=1.99$ & $p<0.05$ & 1.50 & $0.00,3.00$ \\
\hline \multirow[t]{2}{*}{$\begin{array}{l}\text { Maximal } \\
\text { flexion }\end{array}$} & $\begin{array}{l}\text { absence of feelings of } \\
\text { inferiority }\end{array}$ & improved & 53 & 19.00 & $(2.50)$ & 20.00 & $(2.00)$ & $z=1.79$ & $p=0.07$ & -1.00 & $-2.00,0.00$ \\
\hline & $(6-30)$ & non-improved & 12 & 19.00 & $(1.50)$ & 18.00 & $(1.75)$ & $z=1.97$ & $p<0.05$ & 2.00 & $0.00,3.00$ \\
\hline \multirow{4}{*}{$\begin{array}{l}\text { Maximal } \\
\text { extension }\end{array}$} & sense of comfort & improved & 55 & 37.00 & $(4.50)$ & 39.00 & $(5.00)$ & $z=0.76$ & N.S & -0.50 & $-2.50,1.00$ \\
\hline & $(11-55)$ & non-improved & 10 & 40.50 & $(3.88)$ & 37.00 & $(5.75)$ & $z=1.68$ & $p=0.09$ & 4.00 & $-2.00,10.00$ \\
\hline & $\begin{array}{l}\text { feelings of acceptance } \\
\text { and trust }\end{array}$ & improved & 55 & 18.00 & $(1.50)$ & 18.00 & $(1.10)$ & $z=1.37$ & N.S & -0.90 & $-1.50,0.50$ \\
\hline & $(6-30)$ & non-improved & 10 & 18.00 & $(3.88)$ & 15.00 & $(5.88)$ & $z=1.69$ & $p=0.09$ & 3.50 & $-1.50,7.50$ \\
\hline
\end{tabular}

The quartile deviation indicates half of the interquartile range 
Prior research has shown that good body alignment leads to improved stability with adequate distribution between muscular, skeletal, and nerve loads and maximizes also energy efficiency (Kendall et al., 2010; Diebo et al., 2015). According to several studies on posture in children, common postural deviations found in at least $50 \%$ of healthy children include the forward head posture, knee hyperextension and valgus, pelvic anteversion, pelvic tilt, protruding shoulders, scapula abduction, and winged shoulder blades (Penha et al., 2005 Batistão et al., 2016; Czaprowski et al., 2018). Postural characteristics of the participants in this study included an anteriorly protruding head position $(90.8 \%)$ and an anteriorly tilted trunk position (72.3\%). Through the postural modification program, the participants could bring their head and trunk closer to the vertical position. More specifically, changes from the forward to vertical position were found to be exhibited by $60 \%$ of the participants with forward head posture and $70.8 \%$ of participants with forward inclination of the trunk. Regarding the load added to the intervertebral disc, the load applied to the lower lumbar vertebrae increases when bending forward compared to a normal standing position (Sato et al., 1999; Wilke et al., 1999). For this reason, bringing the head and trunk to the vertical position leads to a reduction of the load to the lower back. Furthermore, research regarding stress to the cervical spine caused by posture and head position has found that the weight to the spine dramatically increases when flexing the head forward (Hansraj, 2014). In the head forward posture, the activity of the extension muscle group (e.g., trapezius) increases to keep the head up. Thus, changing the head position closer to the trunk reduces the burden on neck extensor muscles and tendon organizations.

Several studies have shown that muscle hardness and stiffness can decrease through static muscle stretching (Nakamura et al., 2014; Taniguchi et al., 2015). In the present study, static stretching was used to relieve stiffness in the diaphragm and scalene muscle which are integral in maintaining posture and breathing given that the diaphragm contributes to postural stability by increasing abdominal pressure. The activity of the diaphragm in respiratory movements involves an expansion movement of the thorax and abdomen produced by inhalation, altering intra-abdominal pressure and simultaneously altering thoracic motion. Thus, increasing the flexibility of the diaphragm can positively improve respiration in addition to improving posture. Moreover, the scalene muscle connecting the upper ribs with the cervical vertebra is related to the anteflexion and rotation of the head and functions to expand the upper thorax by pulling the first and second ribs. In the forward head posture, the activity of the extension muscle group (e.g., trapezius) increases, whereas the scalene and sternocleidomastoid muscle shorten. Thus, increasing the flexibility of the scalene muscle can improve respiratory movement as well as allow for the head to move easily in longitudinal and lateral directions. This study shows that the postural modification program was able to adjust or approach the subject's posture to the ideal physiological alignment. However, it should be noted that the relationship between posture and breathing needs to be further studied.

What is noteworthy in the present study is that the psychological changes associated with postural intervention were examined using the GHQ and SAS. The aim of the GHQ is to examine whether normal psychological functioning has been maintained or whether new events since the last test have caused the participant distress. If the GHQ score is high, this tends to show that a symptom is serious and that the degree of seriousness is generally in proportion to the GHQ score. On the other hand, the SAS assessed the subjective adjustment of adolescents to school life. If the SAS score is high, it is more likely that the participant will exhibit a positive adjustment to school life.

The finding of this study is that the effects of the postural intervention on psychological change is limited but positive. The GHQ total scores showed a decreasing trend, suggesting a good effect of the postural intervention on physical and psychological health. In particular, a significant improvement was observed in social activity disorder (e.g., questionnaire items related to social action). After the posture intervention, increased flexibility and changes in the posture maintenance of the head and trunk were observed. It is highly likely that reduction in physical load, the ease of maintenance posture and breathing were reflected in the physical and psychological health status indicated by the GHQ.

In the prior studies examining the psychological effects of postural interventions, HwangBo (2016) showed positive effects in Cobb angle improvement and depression and selfesteem with the Schroth and Pilates Exercise for high school girls with Idiopathic scoliosis. Harvey et al. (2020) also found that postural feedback training improved subjective posture and the SF-36 in physical functioning, emotion, energy/fatigue, confidence, and overall stress ratings. The present study, like these previous studies, shows that postural intervention helps improve mental health, but not all psychological indicators showed significant improvement. Since there are individual differences in the degree of subjective sensation of physical changes, general illness, somatic symptoms, sleep disturbance, anxiety, and dysphoria may not have been significantly improved.

To examine the psychological states related to postural improvement, participants were classified into the improved postural group and the non-improved postural group, and comparisons were made before and after the intervention. As a result, in terms of adaptation to the environment (and, more specifically, the subjective adjustment to school), the SAS score was found to be higher in the improved group, with an improvement concerning the sense of comfort, the feelings of acceptance and trust, and absence of feelings of inferiority. On the other hand, those scores in the non-improve group declined. The subjective adjustment to school is greatly influenced by the relationship with classmates and academic 
performance. In other words, even though improving posture alone does undramatically improve school adjustment, it is useful to suggest that the effects of improving posture include not only improving school adjustment but also preventing school adjustment from declining. These psychological aspects indicated by the GHQ and SAS are suggested to represent the motivation for daily life. It is presumed that postural intervention increased flexibility, changed the posture of the head and trunk, reduced physical load, and made it easier to perform posture maintenance and breathing exercises, which increased motivation for daily life, especially in those who recognized the improvement in posture, led to an increase in the sense of adjustment to school.

The results from this study indicate that improved posture positively influences objective physical aspects, subjective physical and psychological health conditions, and adjustment to school. The authors, therefore, conclude that the postural modification program is one of the valuable approaches to support the physical and psychological health of school refusal students and their growth. Note that the control group (condition) could not be established because of its educational practice in this study. To confirm the exact effects of the postural intervention, verifications by randomized controlled trials would be necessary.

A limitation of the present study to consider is that the posture of several students who participated in the study did not improve. This requires further consideration of the current intervention approach: both the frequency of intervention and the quality of the postural intervention. In addition, it was suggested that postural maintenance and respiratory movement became easier to perform post-intervention; however, not enough data could be obtained to establish this strongly. These issues should be considered further in future research.

\section{Conclusion}

We found that easy-to-implement postural interventions have a positive effect on students' mental health. Furthermore, it was suggested that their adjustment to school life would also improve as their posture improved. The contribution of this study shows that it is possible to care for the physical and mental health of students without using special facilities and techniques. It is hoped that the findings of this study will lead to an improved adjustment to both school or novel environments, as well as prevent health-based school refusal.

Abbreviations GHQ, General health questionnaire 30; SAS, Subjective adjustment scale.

Acknowledgments We appreciate the high school students who participated in the study for their cooperation and also the support of their teachers.
Authors' Contributions $\mathrm{MM}$ and SO were involved in the design of this study. MM, EY, and GH contributed significantly in terms of measurement and analysis of data and interpretation of the results. MM wrote the first draft of the manuscript, and all other authors edited and approved the final manuscript.

Data Availability Data and materials are available from the corresponding author on a reasonable request.

\section{Declaration}

Ethics Approval and Consent to Participate This study was approved by The Research Ethics Committee of The International Pacific University. We provided all participants with full disclosure and explanation of the purpose and procedure of this study. Then written informed consent was obtained from all the participants and their parents.

Consent for Publication Not applicable.

Competing Interests The authors declare that they have no competing interests.

Open Access This article is licensed under a Creative Commons Attribution 4.0 International License, which permits use, sharing, adaptation, distribution and reproduction in any medium or format, as long as you give appropriate credit to the original author(s) and the source, provide a link to the Creative Commons licence, and indicate if changes were made. The images or other third party material in this article are included in the article's Creative Commons licence, unless indicated otherwise in a credit line to the material. If material is not included in the article's Creative Commons licence and your intended use is not permitted by statutory regulation or exceeds the permitted use, you will need to obtain permission directly from the copyright holder. To view a copy of this licence, visit http://creativecommons.org/licenses/by/4.0/.

\section{References}

Adams, M. A., Dolan, P., \& McNally, D. S. (2009). The internal mechanical functioning of intervertebral discs and articular cartilage, and its relevance to matrix biology. Matrix Biology, 28(7), 384-389. https://doi.org/10.1016/j.matbio.2009.06.004.

Barrey, C., Roussouly, P., Le Huec, J. C., D'Acunzi, G., \& Perrin, G. (2013). Compensatory mechanisms contributing to keep the sagittal balance of the spine. European Spine Journal, 22(Suppl 6), S834S841. https://doi.org/10.1007/s00586-013-3030-z.

Batistão, M.V., Moreira, R.F.C., Coury, H.J.C.G., Salasar, L.E.B., Sato, T.O. (2016). Prevalence of postural deviations and associated factors in children and adolescents: a cross-sectional study. Fisioter mov, 29(4), 777-785. https://doi.org/10.1590/1980-5918.029.004. ao14.

Blondel, B., Schwab, F., Ungar, B., Smith, J., Bridwell, K., Glassman, S., Shaffrey, C., Farcy, J. P., \& Lafage, V. (2012). Impact of magnitude and percentage of global sagittal plane correction on health-related quality of life at 2-years follow-up. Neurosurgery, 71(2), 341-348; discussion 348. https://doi.org/10.1227/NEU.0b013e31825d20c0.

Breuner, C. C., Smith, M. S., \& Womack, W. M. (2004). Factors related to school absenteeism in adolescents with recurrent headache. Headache, 44(3), 217-222. https://doi.org/10.1111/j.1526-4610. 2004.04050.x.

Chalkiadis, G. A. (2001). Management of chronic pain in children. The Medical Journal of Australia, 175(9), 476-479. 
Chansirinukor, W., Wilson, D., Grimmer, K., \& Dansie, B. (2001). Effects of backpacks on students: Measurement of cervical and shoulder posture. The Australian Journal of Physiotherapy, 47(2), 110-116. https://doi.org/10.1016/s0004-9514(14)60302-0.

Czaprowski, D., Stolinski, L., Tyrakowski, M., Kozinoga, M., \& Kotwicki, T. (2018). Non\structural misalignments of body posture in the sagittal plane. Scoliosis Spinal Disord, 13, 6. https://doi.org/ 10.1186/s13013-018-0151-5.

Diebo, B. G., Varghese, J. J., Lafage, R., Schwab, F. J., \& Lafage, V. (2015). Sagittal alignment of the spine: What do you need to know? Clinical Neurology and Neurosurgery, 139, 295-301. https://doi. org/10.1016/j.clineuro.2015.10.024.

Egger, H. L., Costello, E. J., \& Angold, A. (2003). School refusal and psychiatric disorders: A community study. Journal of the American Academy of Child and Adolescent Psychiatry, 42(7), 797-807. https://doi.org/10.1097/01.CHI.0000046865.56865.79.

Feldman, D. E., Shrier, I., Rossignol, M., \& Abenhaim, L. (2001). Risk factors for the development of low back pain in adolescence. American Journal of Epidemiology, 154(1), 30-36. https://doi.org/ 10.1093/aje/154.1.30.

Gamble, B., \& Crouse, D. (2020). Strategies for supporting and building student resilience in Canadian secondary and post-secondary educational institutions. SciMedicine Journal, 2(2), 70-76. https://doi.org/ 10.28991/SciMedJ-2020-0202-4.

Gibler, R. C., Beckmann, E. A., Lynch-Jordan, A. M., Kashikar-Zuck, S., \& Mano, K. E. J. (2019). Characterizing social and academic aspects of school anxiety in pediatric chronic pain. The Clinical Journal of Pain, 35(7), 625-632. https://doi.org/10.1097/AJP. 0000000000000720 .

Glaser, R., \& Kiecolt-Glaser, J. K. (2005). Stress-induced immune dysfunction: Implications for health. Nature Reviews. Immunology, 5(3), 243-251. https://doi.org/10.1038/nri1571.

Gonzalvez, C., Kearney, C. A., Jimenez-Ayala, C. E., Sanmartin, R., Vicent, M., Ingles, C. J., et al. (2018). Functional profiles of school refusal behavior and their relationship with depression, anxiety, and stress. Psychiatry Research, 269, 140-144. https://doi.org/10.1016/ j.psychres.2018.08.069.

Griegel-Morris, P., Larson, K., Mueller-Klaus, K., \& Oatis, C. A. (1992). Incidence of common postural abnormalities in the cervical, shoulder, and thoracic regions and their association with pain in two age groups of healthy subjects. Physical Therapy, 72(6), 425-431. https://doi.org/10.1093/ptj/72.6.425.

Hansraj, K. K. (2014). Assessment of stresses in the cervical spine caused by posture and position of the head. Surgical Technology International, 25, 277-279.

Harrison, D. E., Colloca, C. J., Harrison, D. D., Janik, T. J., Haas, J. W., \& Keller, T. S. (2005). Anterior thoracic posture increases thoracolumbar disc loading. European Spine Journal, 14(3), 234 242. https://doi.org/10.1007/s00586-004-0734-0.

Harvey, R. H., Peper, E., Mason, L., \& Joy, M. (2020). Effect of posture feedback training on health. Applied Psychophysiology and Biofeedback, 45, 59-65. https://doi.org/10.1007/s10484-02009457-0.

Hochadel, J., Frolich, J., Wiater, A., Lehmkuhl, G., \& FrickeOerkermann, L. (2014). Prevalence of sleep problems and relationship between sleep problems and school refusal behavior in schoolaged children in children's and parents' ratings. Psychopathology, 47(2), 119-126. https://doi.org/10.1159/000345403.

HwangBo, P. N. (2016). Psychological and physical effects of Schroth and Pilates exercise on female high school students with idiopathic scoliosis. J Kor Phys The, 28(6), 364-368. https://doi.org/10.18857/ jkpt.2016.28.6.364.

Jastrowski Mano, K. E. (2017). School anxiety in children and adolescents with chronic pain. Pain Research \& Management, 8328174 , 1-9. https://doi.org/10.1155/2017/8328174.
Kendall, F. P., McCreary, E. K., \& Provance, P. G. (2010). Muscles: testing and function with posture and pain: Lippincott Williams \& Wilkins.

Knight, S. J., Politis, J., Garnham, C., Scheinberg, A., \& Tollit, M. A. (2018). School functioning in adolescents with chronic fatigue syndrome. Frontiers in Pediatrics, 6, 302. https://doi.org/10.3389/fped. 2018.00302.

Lee, S. H. (2020). A community arts program for underserved children: Getting things done and member development. SciMedicine Journal, 2(3), 138-150. https://doi.org/10.18857/jkpt.2016.28.6. 364.

Mackenzie, W. G., Sampath, J. S., Kruse, R. W., \& Sheir-Neiss, G. J. (2003). Backpacks in children. Clinical Orthopaedics and Related Research, 409, 78-84. https://doi.org/10.1097/01.blo.0000058884. 03274.d9.

Mayoux-Benhamou, M. A., \& Revel, M. (1993). Influence of head position on dorsal neck muscle efficiency. Electromyography and Clinical Neurophysiology, 33(3), 161-166.

Miike, T., Tomoda, A., Jhodoi, T., Iwatani, N., \& Mabe, H. (2004). Learning and memorization impairment in childhood chronic fatigue syndrome manifesting as school phobia in Japan. Brain Dev, 26(7), 442-447. https://doi.org/10.1016/j.braindev.2003.10.004.

Murphy, S., Buckle, P., \& Stubbs, D. (2004). Classroom posture and selfreported back and neck pain in schoolchildren. Applied Ergonomics, 35(2), 113-120. https://doi.org/10.1016/j.apergo.2004.01.001.

Nair, S., Sagar, M., Sollers 3rd, J., Consedine, N., \& Broadbent, E. (2015). Do slumped and upright postures affect stress responses? A randomized trial. Health Psychology, 34(6), 632-641. https:// doi.org/10.1037/hea0000146.

Nakagawa, Y., \& Daibou, I. (1985). Japanese version of the general health questionnaire. Nihon Bunka Kagakusha (in Japanese).

Nakamura, M., Ikezoe, T., Kobayashi, T., Umegaki, H., Takeno, Y., Nishishita, S., \& Ichihashi, N. (2014). Acute effects of static stretching on muscle hardness of the medial gastrocnemius muscle belly in humans: An ultrasonic shear-wave elastography study. Ultrasound in Medicine \& Biology, 40(9), 1991-1997. https://doi. org/10.1016/j.ultrasmedbio.2014.03.024.

Neumann, D. A., Kelly, E. R., Kiefer, C. L., Martens, K., \& Grosz, C. M. (2017). Kinesiology of the musculoskeletal system: foundations for rehabilitation: Elsevier.

Ohashi, S., \& Kaneko, E. (2014). A qualitative research paper on the development of psychological resilience and adjustment to the school environment, of high school students who were classified as school non-attendees. Bulletin of International Pacific University, 9, 307-318. https://doi.org/10.24767/00000465 (in Japanese).

Okubo, T. (2005). Factors contributing to subjective adjustment to school in adolescents. Japanese Journal of Educational Psychology, 53, 307-319. https://doi.org/10.5926/jjep1953.53.3_307 (in Japanese).

Paranjape, S., \& Singhania, N. (2019). Effect of body positions on quadriceps angle measurement. SciMedicine Journal, 1(1), 20-24. https://doi.org/10.28991/SciMedJ-2019-0101-3.

Penha, P. J., João, S. M. A., Casarotto, R. A., Amino, C. J., \& Penteado, D. C. (2005). Postural assessment of girls between 7 and 10 years of age. Clinics, 60(1), 9-16. https://doi.org/10.1590/S180759322005000100004 .

Romani, J., Campredon, S., \& Da Fonseca, D. (2017). School refusal: Psychopathological profiles of adolescents followed in a day hospital setting. Archives de Pédiatrie, 24(10), 950-959. https://doi.org/ 10.1016/j.arcped.2017.08.003.

Rousseau-Salvador, C., Amouroux, R., Annequin, D., Salvador, A., Tourniaire, B., \& Rusinek, S. (2014). Anxiety, depression and school absenteeism in youth with chronic or episodic headache. Pain Research \& Management, 19(5), 235-240. https://doi.org/10. 1155/2014/541618. 
Santonja-Medina, F., Collazo-Dieguez, M., Martinez-Romero, M. T., Rodriguez-Ferran, O., Aparicio-Sarmiento, A., Cejudo, A., et al. (2020). Classification system of the sagittal integral Morphotype in children from the ISQUIOS Programme (Spain). International Journal of Environmental Research and Public Health, 17(7). https://doi.org/10.3390/ijerph17072467.

Sato, K., Kikuchi, S., \& Yonezawa, T. (1999). In vivo intradiscal pressure measurement in healthy individuals and in patients with ongoing back problems. Spine (Phila Pa 1976), 24(23), 2468-2474. https:// doi.org/10.1097/00007632-199912010-00008.

Sheir-Neiss, G. I., Kruse, R. W., Rahman, T., Jacobson, L. P., \& Pelli, J. A. (2003). The association of backpack use and back pain in adolescents. Spine (Phila Pa 1976), 28(9), 922-930. https://doi.org/10. 1097/01.BRS.0000058725.18067.F7.

Taniguchi, K., Shinohara, M., Nozaki, S., \& Katayose, M. (2015). Acute decrease in the stiffness of resting muscle belly due to static stretching. Scandinavian Journal of Medicine \& Science in Sports, 25(1), 32-40. https://doi.org/10.1111/sms.12146.
Tomoda, A., Miike, T., Yonamine, K., Adachi, K., \& Shiraishi, S. (1997). Disturbed circadian core body temperature rhythm and sleep disturbance in school refusal children and adolescents. Biological Psychiatry, 41(7), 810-813. https://doi.org/10.1016/S00063223(96)00179-5.

Widhe, T. (2001). Spine: Posture, mobility and pain. A longitudinal study from childhood to adolescence. European Spine Journal, 10(2), 118-123. https://doi.org/10.1007/s005860000230.

Wilke, H. J., Neef, P., Caimi, M., Hoogland, T., \& Claes, L. E. (1999). New in vivo measurements of pressures in the intervertebral disc in daily life. Spine (Phila Pa 1976), 24(8), 755-762. https://doi.org/10. 1097/00007632-199904150-00005.

Publisher's Note Springer Nature remains neutral with regard to jurisdictional claims in published maps and institutional affiliations. 